Pontificia Univergidade Católica $_{\text {a }}$ DO RIO DE JAMEIRO

\author{
Livia Maria Aires de Castro
}

\title{
Escrita e letramento no Ensino Médio: Uma abordagem sistêmico-funcional e de Linguística Aplicada
}

\section{Dissertação de Mestrado}

Dissertação de Mestrado apresentada como requisito parcial para obtenção do grau de Mestre pelo Programa de Pós-Graduação em Letras do Departamento de Letras do Centro de Teologia e Ciências Humanas da PUC-Rio.

Orientadora: Profa. Lúcia Pacheco de Oliveira

Rio de Janeiro

Setembro de 2009 


\section{Pontificia Universidade Católica DO RIO DE JANEIRO}

\section{Livia Maria Aires de Castro}

\section{Escrita e letramento no Ensino Médio:Uma abordagem sistêmico-funcional e de Linguística Aplicada}

Dissertação de Mestrado apresentada como requisito parcial para obtenção do grau de Mestre pelo Programa de Pós-Graduação em Letras do Departamento de Letras do Centro de Teologia e Ciências Humanas da PUC-Rio. Aprovada pela Comissão Examinadora abaixo assinada.

Profa. Lúcia Pacheco de Oliveira

Orientadora

Departamento de Letras - PUC-Rio

Profa. Inés Kayon de Miller Departamento de Letras - PUC-Rio

Profa. Myriam Brito Corrêa Nunes UFRJ

Prof. Paulo Fernando Carneiro de Andrade Coordenador Setorial do Centro de Teologia e Ciências Humanas - PUC-Rio 
Todos os direitos reservados. É proibida a reprodução total ou parcial do trabalho sem autorização da universidade, da autora e da orientadora.

Livia Maria Aires de Castro

Graduou-se em Letras (Português/Francês) pela Universidade do Estado do Rio de Janeiro em 2003. Integra o grupo de pesquisa Escrita e Inclusão Social: Análise de Corpus e Metáfora Gramatical no Ensino Médio (FAPERJ) desde 2008. Atua principalmente nas áreas de língua portuguesa, língua francesa, língua inglesa e linguística aplicada. Ministrou aulas de português como língua estrangeira no Lycée Montaigne e no Lycée Martin Nadaud, ambos em Paris. Trabalhou por quase dez anos com o ensino de língua inglesa e por quase cinco anos com o ensino de língua francesa, e atualmente exerce o cargo de professora de português como língua materna no ensino fundamental e médio na rede pública de ensino da Prefeitura da Cidade do Rio de Janeiro e do Estado do Rio de Janeiro.

\section{Ficha Catalográfica}

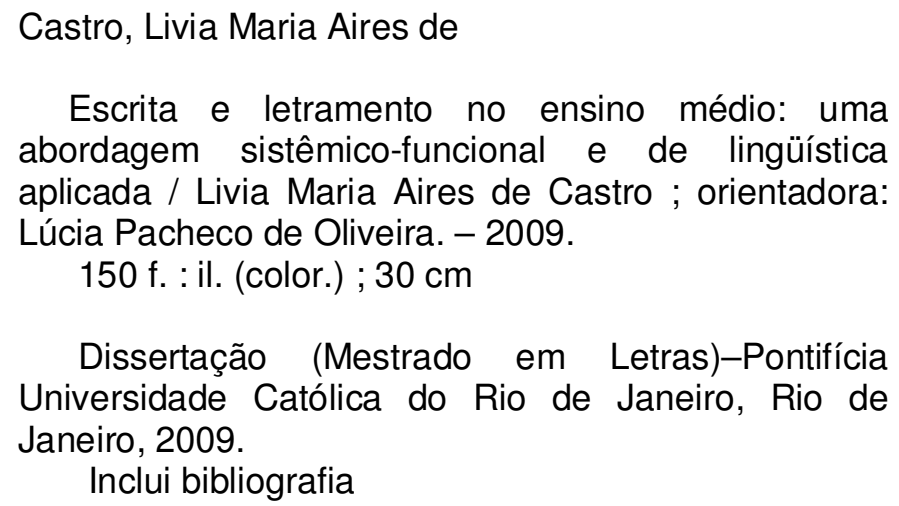
abordagem sistêmico-funcional e de lingüística aplicada / Livia Maria Aires de Castro ; orientadora: Lúcia Pacheco de Oliveira. - 2009.

150 f. : il. (color.) ; $30 \mathrm{~cm}$

Dissertação (Mestrado em Letras)-Pontifícia Universidade Católica do Rio de Janeiro, Rio de Janeiro, 2009.

Inclui bibliografia

1. Letras - Teses. 2. Língua portuguesa. 3. Escrita. 4. Ensino médio. 5. Letramento. 6. Metáfora gramatical. 7. Nominalização. 8. Linguística sistêmicofuncional. 9. Linguística aplicada. I. Oliveira, Lúcia Pacheco de. II. Pontifícia Universidade Católica do Rio de Janeiro. Departamento de Letras. III. Título. 
À minha mãe, pelo apoio incondicional em todos os momentos e projetos e sem a qual este trabalho não existiria, pois nem mesmo teria razão de ser. 


\section{Agradecimentos}

À Profa. Dra. Lúcia Pacheco de Oliveira, pela orientação acadêmica, pela convivência afetuosa e gentil, pela paciência, pela generosidade intelectual e pessoal, pelo incentivo e apoio em absolutamente todos os momentos.

Às Profas. Dras. Inés Kayon de Miller, Myriam Brito Corrêa Nunes e Maria de Fátima Duarte Henrique dos Santos, por terem gentilmente aceitado o convite para integrar a banca examinadora desta dissertação.

Aos alunos das turmas 1007 e 3011 do ano de 2008 do Colégio Estadual Madre Teresa de Calcutá, por terem gentilmente aceitado colaborar dedicando parte de seu tempo à produção dos textos escritos que tornaram este estudo real.

À direção do Colégio Madre Teresa de Calcutá, que permitiu que os exercícios para a geração de dados fossem realizados nesta escola.

Ao Prof. Dr. Décio Orlando Soares da Rocha, pela orientação na monitoria em Linguística durante meus estudos de graduação e pela inspiração para seguir a carreira acadêmica.

À PUC-Rio, pela bolsa de isenção concedida.

Aos Profs. Drs. Décio Orlando Soares da Rocha e Kátia Ferreira Fraga, por terem tão bem me recomendado, pelo pronto auxílio em todos os momentos em que precisei e pelo incentivo desde 1999, ano em que tive o prazer de ser sua aluna pela primeira vez. 
Às Profas. Dras. Barbara Hemais, Inés K. Miller, Liliana Cabral Bastos, Lúcia Pacheco de Oliveira, Maria Paula Frota e Violeta Quental, por suas aulas durante o curso de Mestrado, fomentando minha formação.

A Francisca Ferreira de Oliveira, a "Chiquinha", pela paciência, pela colaboração e pela prontidão em procurar atender a todos os pedidos e solicitações, mesmo aqueles mais difíceis.

A José Pereira de Sá Neto, noivo, namorado, amigo, e acima de tudo companheiro, nos momentos felizes e vitoriosos, mas também naqueles de fraqueza e doença, quando as adversidades quase me deixaram desistir. $\mathrm{O}$ meu muito obrigada por não me deixar desistir do meu sonho, e por acreditar em mim quando nem eu mesma podia mais.

A Nara Fernandes dos Santos, amiga de tanto tempo e de todas as horas, obrigada pelas palavras doces e também pelas duras, pelo ombro amigo e por tentar me trazer de volta à realidade.

Às amigas Bianca Ferreira da Silva, Elisabete Oliveira da Silva, Letícia Oliveira Freitas, Rubenilda de Menezes e Vanessa Villardi, por estarem ao meu lado, por respeitarem as minhas escolhas e entenderem (quase sempre) as minhas ausências. Cada uma a seu modo e de uma maneira específica contribuiu não só para esse projeto, mas para que eu me tornasse a pessoa que sou hoje.

A Milena Mendes Pereira, pelas caronas, por ouvir meus desabafos, por entender e partilhar as minhas angústias e simplesmente por ser um modelo para mim.

A Fernando Fragas, pelo apoio, pela compreensão e pela prontidão em me ajudar nas revisões.

A Nélio Giorgini, pelo incentivo e apoio.

A todos os amigos e familiares que me apoiaram e incentivaram. 
A Alice de Moraes (in memorian), minha avó, por tudo aquilo de que abriu mão para que eu me tornasse o que sou hoje. Pelo carinho incansável e pelo desejo genuíno do melhor para mim.

A Sonia Maria de Moraes Quadrate, minha mãe, por ter tornado tudo isso possível. Por ter se alegrado nas minhas vitórias e por ter chorado ainda mais do que eu nas minhas derrotas. Por ter feito tudo por mim, mesmo nas mais adversas condições, por ter ficado quando todos já tinham partido, por ser a pessoa que mais amo, respeito e admiro nesta vida. 


\section{Resumo}

Castro, Livia Maria Aires de; Oliveira, Lúcia Pacheco de. Escrita e letramento no Ensino Médio: uma abordagem sistêmico-funcional e de Linguística Aplicada. Rio de Janeiro, 2009. 150p. Dissertação de Mestrado - Departamento de Letras, Pontifícia Universidade Católica do Rio de Janeiro.

O presente trabalho visa investigar a produção escrita de alunos de uma escola pública da rede estadual do Rio de Janeiro, buscando observar o grau de letramento em língua portuguesa como primeira língua, apresentado por esses alunos ao ingressarem no Ensino Médio e quando estão prestes a conclui-lo. A pesquisa insere-se na área de Linguística Aplicada, voltada para a relevância social do uso da língua (Moita Lopes, 2006), adotando uma abordagem textual à escrita (Hyland, 2002) e seguindo pressupostos teórico-metodológicos da Lingüística Sistêmico-Funcional, que se ocupa do estudo da língua enquanto sistema de significados e suas funções nos contextos culturais e situacionais. Enfocando o estudo do uso da metáfora gramatical (Halliday, 1994) em textos escolares, através do emprego de nominalizações, este trabalho propõe as seguintes questões: 1) Os alunos do Ensino Médio empregam a metáfora gramatical em seus textos produzidos em sala de aula? 2) O uso de uma linguagem gramaticalmente mais metafórica aumenta durante o ciclo do Ensino Médio? 3) O uso de nominalizações contribui para a melhoria no letramento dos alunos? O conjunto de textos analisados neste estudo consiste em um questionário social, respondido por 40 (quarenta) alunos de duas turmas, uma do primeiro ano e outra do terceiro ano, para que possamos entender quem são os sujeitos sóciohistoricamente construídos, que compõem estas salas de aula. Exercícios de transformações de estruturas verbais em nominais foram feitos por alunos do primeiro ano e do terceiro do Ensino Médio, e analisados para observar o domínio da metáfora gramatical através do uso de nominalizações. Redações escritas por esses alunos $(\mathrm{N}=50)$ também foram analisadas com o objetivo de verificar o uso 
da metáfora gramatical no momento da elaborar os textos escritos em sala de aula. Os resultados da pesquisa indicam que os alunos apresentam um maior domínio da metáfora gramatical quando chegam ao terceiro ano, entretanto não fazem uso de uma linguagem gramaticalmente mais metafórica ao redigir seus textos em sala de sala de aula, mostrando certa dificuldade em fazer uso amplo de transformações gramaticais na escrita.

\section{Palavras-chave}

Língua portuguesa; escrita; ensino médio; letramento; metáfora gramatical; nominalização; linguiística sistêmico-funcional; linguística aplicada. 


\section{Abstract}

Castro, Livia Maria Aires de; Oliveira, Lúcia Pacheco de (Advisor). Writing and literacy in secondary school: A systemic-functional and applied linguistic approach. Rio de Janeiro, 2009. 150p. MSc. Dissertation - Departamento de Letras, Pontifícia Universidade Católica do Rio de Janeiro.

The present work aims at investigating the written production of students at a state school in Rio de Janeiro, in order to verify the degree of literacy in Portuguese as a first language of the students as they enroll in secondary school and when they are about to complete it. This Applied Linguistics research, emphasizes the social relevance of the use of language (Moita Lopes, 2006), adopting a textual approach to writing (Hyland, 2002) and following theoretical and methodological assumptions of Systemic-Functional Linguistics, which views language as a system of meanings and functions in both situational and cultural contexts. Focusing on the study of the use of grammatical metaphor (Halliday, 1994) in school texts, through the use of nominalizations, this research proposes the following questions: 1) Do students in secondary school employ the grammatical metaphor in their texts produced in the classroom? 2) Does the use of a more grammatically metaphorical language increase during the cycle of high school? 3) Does the use of nominalizations help to improve the students' literacy? The set of texts analyzed in this study consists of a social questionnaire, answered by 40 (forty) students in two classes, one of the first year and the other of the third year, so that we could understand who the socio-historically constructed subjects that compound these classrooms are. Exercises that aim at transforming verbal structures into nominal were done by students of the first and third years of secondary school, and analyzed to observe the control of grammatical metaphor through the use of nominalizations. Essays written by these students $(\mathrm{N}=50)$ were also analyzed with the purpose of verifying the use of grammatical metaphor while writing the texts in the classroom. Research results indicate that students have a greater control of grammatical metaphor when they achieve the third year 
of secondary school. However, they do not use a more grammatically metaphorical language to write their texts in the classroom, showing certain difficulty of using largely grammatical transformations in writing.

\section{Keywords}

Portuguese language; writing; secondary school; literacy; grammatical metaphor; nominalization; systemic-functional linguistics; applied linguistics. 


\section{Sumário}

1 Introdução

2 Linguística Aplicada e Ensino $\quad 29$

2.1. A relevância social da pesquisa em LA 29

2.2. O lugar da teoria na prática do professor de línguas 34

2.2.1 O que é, por que e como teorizar? 34

$\begin{array}{ll}\text { 2.3. Resumo } & 37\end{array}$

3 Letramento e escrita escolar 38

3.1. Analfabetismo funcional e letramento 39

3.2. Dados e comentários sobre o desempenho escolar dos alunos brasileiros $\quad 44$

3.3. Escrita na escola $\quad 49$

3.4. Resumo 54

4 Linguagem: perspectivas social e semiótica 56

4.1. Perspectiva sócio-cultural 56

4.2. Perspectiva sociossemiótica 58

4.2.1. Considerações sobre a concepção de linguagem e a gramática funcional $\quad 59$

4.2.2. O texto com o texto: visões de texto e contexto 61

4.2.3. Campo, Relação e Modo 62

4.2.4. Significados e funções da linguagem 63

4.2.5. A metáfora gramatical 65

4.2.5.1. Metáfora gramatical ideacional e nominalização 67

4.3. Resumo 69

5 Metodologia 70 
5.1. O ambiente e os participantes da pesquisa 71

5.2. Gerando dados 73

5.2.1. Questionário social 74

5.2.2. Exercícios de transformação de processos verbais em formas nominais $\quad 74$

5.2.3. Redações 76

5.3. O tratamento dos dados e os procedimentos de análise 78

5.4. Resumo 79

6 Análise $\quad 80$

6.1. Quem é esse aluno? 81

6.2. Análise dos exercícios de transformação 87

6.3. Análise das redações 93

6.3.1. Padrões de textos no primeiro ano 99

6.3.2. Padrões de textos no terceiro ano 106

6.4. Resumo 111

7 Considerações Finais 114

8 Referências Bibliográficas 122

9 Anexos 133

9.1. Modelo da autorização a ser assinada pelos alunos para utilização dos textos

9.2. Modelo da autorização a ser assinada pela direção para utilização dos textos

9.3. Exercício de produção de texto utilizado para a geração de dados

9.4. Questionário Social 137

9.5. Questionário social com resultados tabulados 140

9.6. Formas verbais mencionadas no primeiro ano 148

9.7. Formas verbais mencionadas no terceiro ano 150 


\section{Lista de figuras}

Figura 1: Correspondência entre fraseados congruentes e metafóricos 


\section{Lista de Tabelas}

Tabela 1: A natureza da escrita $\quad 50$

Tabela 2: Tipos de investigação textual 51

Tabela 3: distribuição de alunos por idade $\quad 82$

Tabela 4: Número e percentual de famílias assinantes

de algum jornal 82

Tabela 5: Número e percentual de famílias que já foram assinantes de algum jornal $\quad 82$

Tabela 6: Frequência de leitura de jornais pelos alunos e seus familiares $\quad 83$

Tabela 7: Notas atribuídas pelos alunos à leitura 83

Tabela 8: Tipos de textos escritos pelos alunos fora da sala de aula

Tabela 9: Número e percentual de acertos das formas nominais e outras formas mencionadas no terceiro ano 88

Tabela 10: Escala decrescente da frequência de verbos $\quad 90$

Tabela 11: Número e percentual de acertos das formas nominais e outras formas mencionadas no primeiro ano

Tabela 12: Comparação entre percentual de acertos da forma nominal do verbo dissolver

Tabela 13: Comparação entre percentual de acertos da forma nominal dos verbos construir, abster-se, persistir, absolver e condenar no primeiro ano

Tabela 14: Formas verbais plausíveis de nominalização mencionadas no primeiro ano

Tabela 15: Formas verbais plausíveis de nominalização mencionadas no terceiro ano $\quad 96$

Tabela 16: Formas nominais usadas no primeiro ano 97

Tabela 17: Formas nominais usadas no terceiro ano 97 
Tabela 18: Legenda de cores para análise de dados linguísticos nos textos 99

Tabela 19: Padrões de textos no primeiro ano 100

Tabela 20: Padrões de textos no terceiro ano 106 


\title{
Lista de abreviaturas e siglas
}

\author{
ANAEB \\ Avaliação Nacional da Educação Básica \\ FAPERJ \\ Fundação de Amparo à Pesquisa do Estado do Rio de \\ Janeiro \\ GN \\ Grupo Nominal \\ GV \\ Grupo Verbal \\ IBGE \\ Instituto Brasileiro de Geografia e Estatística \\ ILE \\ Inglês como Língua Estrangeira \\ INEP \\ Instituto Nacional de Educação e Pesquisas \\ Educacionais Anísio Teixeira \\ L1 \\ Primeira Língua \\ L2 \\ Segunda Língua \\ LA \\ Linguística Aplicada \\ LE \\ Língua Estrangeira \\ LSF \\ Linguística Sistêmico-Funcional \\ MEC \\ Ministério da Educação e Cultura \\ OCDE \\ Organização para Cooperação e Desenvolvimento \\ Econômico \\ PISA \\ Programme for International Student Assessment \\ PUC-Rio \\ Pontifícia Universidade Católica do Rio de Janeiro \\ SAEB \\ Sistema de Avaliação da Educação Básica \\ UNESCO \\ Organização das Nações Unidas para a Educação, a \\ Ciência e a Cultura
}


[...] proponho uma conscientização social deste educador, que poderá contribuir para a formação geral do aprendiz, tornando-o mais consciente quanto às suas próprias características culturais e quanto à sua força como agente de mudanças dentro de uma comunidade discursiva e dentro da sociedade como um todo.

Lúcia Pacheco de Oliveira, 2000, p. 58 